\title{
Selection for Preservation
}

\section{A Survey of Current Practices in the Field of Preservation}

\author{
Jennifer Hain Teper
}

Library preservation programs are at the precipice of transformation. With the increasing availability of digitized content, and the development of shared print repositories, our perceived obligation to the preservation of individual print copies at an institutional level is shifting to a more shared model. Library preservation professionals must now determine how this is influencing our day to day practices. This paper reviews the data collected from a 2012 survey and interprets that data to show how the availability of digital surrogates, libraries' increasing consideration of shared print holdings, and the perceived value of scarcely held content are all influencing preservation selection.

any library preservation programs are considering the possible ways that 1 national holdings, availability of digital copies, holdings in shared print repositories, and local use can and perhaps should influence the selection of materials for preservation actions such as reformatting, rehousing, and repair. In considering the many ways that these metrics could be incorporated and how they might be applied locally at her institution, the author determined that a survey of current practices in the field would help illuminate this issue. The goal of the survey was to show which general practices are being established among academic/research libraries and to answer the question: How are current preservation programs integrating availability of content outside of their own physical holdings into their preservation workflows? This paper reviews the data collected from the 2012 survey and interprets that data to show how the availability of digital surrogates, libraries' increasing consideration of shared print holdings, and the perceived value of scarcely held content are all influencing preservation selection in North American academic and research libraries.

Jennifer Hain Teper (jhain@illinois.edu) is Head, Preservation and Conservation Units, University of Illinois Libraries.

Manuscript submitted September 24, 2013; returned to author for minor revisions January 14, 2014; revisions submitted February 18, 2014; accepted for publication May 5, 2014

\section{Literature Review}

Practicing librarians, scholars, and academics have been investigating the issues of print retention and digital surrogacy, and the possible positive or negative influences on long-term preservation and access for over just over a decade. While each of these areas frequently overlap and inform each other, within the published literature, the areas of research tend to be relatively distinct. 
Therefore, the following literature review is organized into three discrete subsections: digital surrogacy, print retention, and preservation programs in a changing word.

\section{Digital Surrogacy}

A great deal of attention has been paid to the trustworthiness of digital surrogates in the recent past. The first formal step in the endorsement of digitization as a preservation reformatting method was in the publication Recognizing Digitization as a Preservation Reformatting Method, prepared for the Association of Research Libraries (ARL) Preservation of Research Library Materials. ${ }^{1}$ In this publication, which was quite controversial when it was issued in 2004 , the authors state that though digitization for preservation had been happening in institutions for several years, there were still perceptions that it was not a trustworthy, long-term option. The report presents arguments for well-planned and structured digitization as a sound preservation option. One of the most cited works in this area was published by the Council for Library and Information Resources (CLIR) four years later. ${ }^{2}$ In this seminal article, written only months before the founding of the HathiTrust, Reiger investigated the impact of large-scale digitization initiatives (LSDIs) such as the Google Book Search Project and the Open Content Alliance (OCA) on the way libraries viewed digitization, regarding both scale and long-term accessibility. She also investigated the need for preservation infrastructure in LSDIs, including minimum metadata requirements, quality control, technical and organizational infrastructure, and then considers the implications of LSDIs on physical collections and preservation programs. In closing, Reiger makes sound recommendations for next steps to improve quality and long-term access to LSDI content, which not only paved the way for the success of the HathiTrust, but also the increased importance of shared print repositories and investigations in quality control of LSDI digitized images.

Most recently, Conway has conducted research in the quality of digitized content and the role of digital content within preservation programs. One of his most recent research projects, funded by both the Andrew W. Mellon Foundation and the Institute for Museum and Library Services (IMLS), sought to investigate and quantify the quality of digitized content found in the HathiTrust. His first publication on the subject-a conference paper from the 2010 iPres conference-presents the research framework and method and is followed up by a more thorough presentation of his research plan and implications of the potential findings in Archival Quality and Long-Term Preservation: A Research Framework for Validating the Usefulness of Digital Surrogates. ${ }^{3}$ This project, which concluded in 2013, has yet to release its formal findings, but the implications of the trustworthiness of digital surrogacy weigh heavily on how much faith preservation can place in third-party digitized content.

\section{Print Retention}

There are several schools of thought regarding the role of print retention in research libraries, and all affect preservation in some way. Lack of space has long been an issue for libraries, and many have moved large portions of their lesser-used materials to off-site or high-density storage facilities. However, as those facilities begin to fill, institutions have also investigated shared collection access to help alleviate space issues without dramatically decreasing access to titles. As libraries have considered shared collections, preservation has, by necessity, been part of the conversation from several perspectives. Preceding many and on a regional scale, the Five Colleges (Amherst College, Hampshire College, Mount Holyoke College, Smith College and UMass Amherst) collaborated in a shared print repository (SPR) for their lesser-used holdings where best available copies were selected and marked as copies of record for long-term retention, a model now replicated by many institutions especially for journal titles available electronically through major vendors or organizations such as JSTOR. ${ }^{4}$ Looking beyond local and regional repositories, however, Payne examined the role of library storage facilities in the development of shared journal archives, last and single-copy facilities, and the potential for development of a distributed print repository network utilizing materials in these facilities. ${ }^{5}$ The approach for such repositories has focused largely on serial publications, due to the more stable electronic resource infrastructure related to them. Monographs, however, have remained less of a focus. In response to these findings, a group of institutions and organizations, with IMLS funding, met to develop a framework to help guide shared monographic print retention policies. ${ }^{6}$ Within this guideline, the preservation of an "adequate" number of copies plus the larger-scale preservation issues relating to monographs and their potential use were considered. While no concrete recommendations were provided, the paper presented the most promising scenarios for approaching this effort, which included focusing on materials already in library storage facilities, those materials also in the HathiTrust, or identifying materials by class range, subject and discipline. At the same time, the Maine Shared Collections Strategy project was implemented through an IMLS grant which has as one of its major goals the "Development and implementation of a policy for preservation of unique and rare print materials" in a shared print environment. ${ }^{7}$ This project, due to end in 2014, has thus far released its first retention scenario and a memorandum of understanding (MOU) and may help to lay groundwork for other models to follow. Lastly, although no formal publications have yet been released, the HathiTrust is 
also planning a distributed print monograph archive project, the proposal for which was voted upon at the 2011 Constitutional Convention. ${ }^{8}$ While still in the planning phases, the scope of this project has the potential to have much more far-reaching effect on libraries than any of the other shared print projects to date.

Another perspective on print retention is the discussion of when to discard an item. Whereas the discard of duplicates has always been an option within preservation programs, some institutions have been pursuing this strategy more aggressively than others. First published online as a white paper in 2008, a statistical analysis through University of California Berkeley led to a suggested threshold for print survival over time. ${ }^{9}$ This research directly supported the landmark publication by Schonfeld and Housewright of Ithaka S+R, which crafted explicit recommendations for national print journal retention strategies for US libraries incorporating the availability and preservability of electronic journals as part of those recommendations. ${ }^{10}$ These two analyses were then incorporated into practice at the University of California Los Angeles, and now guide preservation treatment selection or discard decisions in their university library. ${ }^{11}$

\section{Preservation Programs in a Changing World}

Despite the many publications that focus on the relationships between shared print retention and preservation or digital content and preservation, few have offered more holistic publications on how both of these practices are impacting preservation programs. As mentioned above, parts of Reiger's Preservation in the Age of Large-Scale Digitization certainly begin to test these waters, but by far the most comprehensive of those available is Meyer's Safeguarding Collections at the Dawn of the 21st Century, which he wrote while serving as a visiting Program Officer at ARL. ${ }^{12}$ Written just as the ARL was considering dropping the collection of ARL Preservation Statistics (www. arlstatistics.org/about/series/preservation), this paper asks the surprisingly difficult question "what is modern preservation?" and includes the considerations of digital content, the web, and shared storage among others, as necessary in current preservation programs. In his article Preservation in the Age of Google: Digitization, Digital Preservation, and Dilemmas, Conway reviews how the field of preservation has transformed due to the availability of immediate access to digitized content online and the requirements of digital preservation frameworks. ${ }^{13}$ Little has been written in the three years since its publication. In 2013, however, the British Library released "Knowing the Need: Optimising Preservation for Library and Archive Collections." ${ }^{\prime 4}$ This short report, much like Heritage Preservation's Heritage Health Index and the British Library's Knowing the Need: A Report on the Emerging Picture of Preservation Need in Libraries and Archives in the UK (National Preservation Office), summarizes the current state of the preservation of physical collections. ${ }^{15}$ But, unlike its predecessors, the 2013 publication considers surrogate availability compared with condition and usability, and proposes preservation prioritization models utilizing this data.

\section{Surveying the Field}

To answer the question "How are current preservation programs in research libraries integrating availability of content outside of their own physical holdings into their preservation workflows?," the author developed a survey in the summer of 2012. A draft of the survey tool was tested on a select group of nine peer institutions willing to serve in that capacity and modifications were made based on feedback. An invitation to take the survey (available in the appendix) was distributed through various professional discussion lists and remained open from October 24 to November 14, 2012. The survey consisted of thirty questions seeking information grouped into seven general categories: (1) general information; (2) current preservation practices; (3) selection for preservation; (4) print replacement; (5) holdings; (6) digital surrogate; and (7) use.

\section{Survey Results}

\section{General Information}

There were forty-nine responses to the survey and there were no observable multiple responses from any single institution. While this was a respectable number of survey responses, no exact response rate can be drawn from this total, as the number of institutions undertaking these practices is unknown. The respondents were predominantly preservation (65 percent) and conservation (23 percent) professional staff, with smaller representation from preservation (6 percent) and conservation (2 percent) support staff, as well as four percent collection management staff or librarians. Responses represented practices at a variety of institutions of different sizes and types. Seventy-one percent reported from research libraries, while 27 percent were from non-research institutions (though most were academic) —all from the US and Canada. The size of library collections served by the preservation programs was evenly distributed between the various size ranges (represented by volume count, a common statistic gathered by the ARL), with 21 percent under 1 million volumes; 27 percent at 1-3 million volumes; 18 percent at 3-5 million volumes; 16 percent at 5-8 million volumes, and 16 percent at over 8 million volumes. 


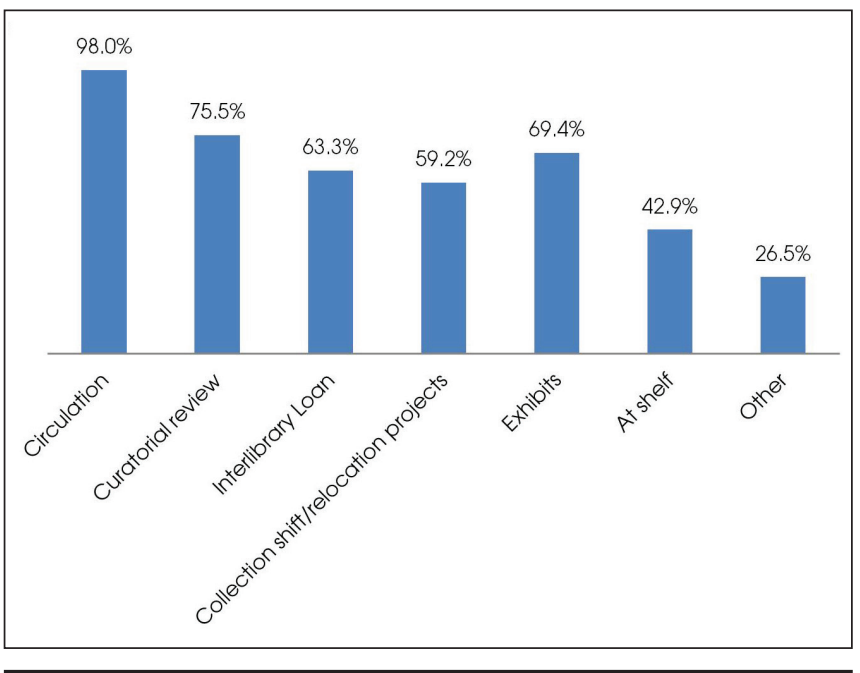

Figure 1. (Question II.4.) Selection of materials for preservation

\section{Preservation and Conservation Practices Represented}

The size of preservation programs, measured in full-time equivalent (FTE) staff ranged from 0.33 to 103 , with a mean of 8.4 FTE and a median of 5.5 FTE. Programs perform a full range of preservation and/or conservation treatments, including special collections conservation treatment (practiced by 80 percent of respondents); general collections conservation treatment/book repair (96 percent); pamphlet binding (94 percent); library binding (88 percent); construction of custom protective enclosures (in house or purchased) (94 percent); preservation reformatting of brittle paper materials through microfilm (33 percent); preservation reformatting of brittle paper materials through digitization (63 percent); and preservation reformatting of brittle paper materials through "preservation photocopy" replacements (67 percent). Seventy-one percent reported finding replacement copies of damaged materials through the used book market; and 63 percent of respondents replied that their program will discard damaged materials even if they are not replaced through reformatting or replacement copies, at least in some instances. Lastly, materials selected for preservation/conservation treatment are identified in a variety of ways, with most institutions (90 percent) reporting that they use combinations of three or more methods for identification. While circulation was by far the most popular method (98 percent of respondents utilized it as a method of selection), only shelf review and various "other" methods were used by less than 50 percent of respondents (see figure 1). "Other" responses included during acquisition, retrospective cataloging projects, transfer to storage, digitization, and through surveys.

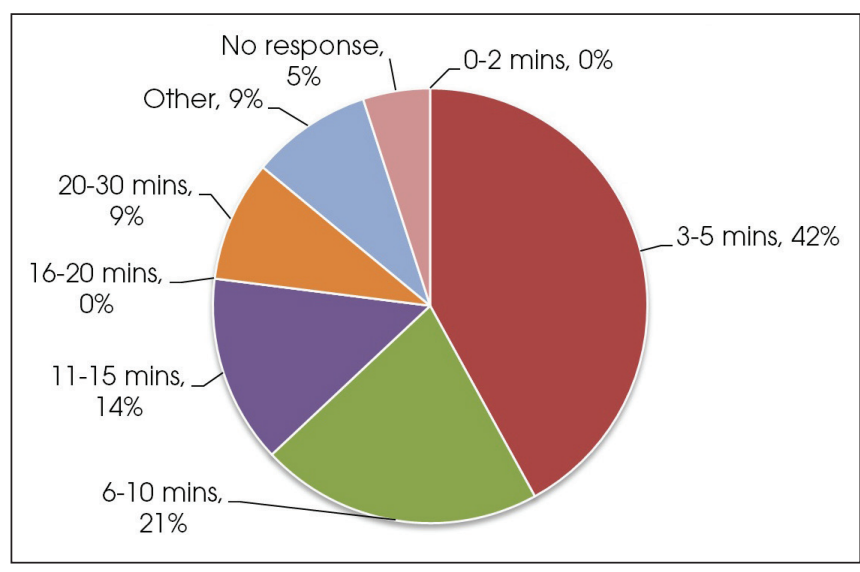

Figure 2. (Question III.4) How much time is spent, on average reviewing preservation metrics before making treatment decisions?

\section{Selection for Preservation Treatment}

After basic institutional and program demographics, the survey gathered more specific information on preservation review and prioritization practices. Overall, most preservation and conservation programs spend some time reviewing shared metrics before making treatment decisions. The first questions of this portion of the survey asked if respondents do any one of the following: (1) search for print replacement copies; (2) search for the availability of national, regional, or consortial holdings; (3) search for the availability of digitized content; or (4) collect historical circulation/use statistics. Of the responses, only 10 percent replied that they did not utilize at least some of these metrics when evaluating one or more workflows in preservation. The majority (42 percent of respondents) spend only 3-5 minutes reviewing this data. However, some institutions take much more time for review and interpretations, ranging from 6 to 10 minutes (31 percent), 11 to 15 minutes (14 percent), 16 to 20 minutes $(0$ percent), to 20 to 30 minutes (9 percent). For the 9 percent that responded with "other," most offered that they had more than one workflow and that searching varied between those, ranging from no review to up to forty minutes per item (see figure 2). Although one might assume that institutions with more staff in preservation were more likely to do more in-depth searching, there was no correlation to support that assumption. Surprisingly, the total FTE for those taking more than ten minutes per item to search was just under 2.0 FTE lower (at 5.6 FTE total program staff) than those taking between 1 and 10 minutes (at 7.4 FTE).

Not all workflows utilize input from such searches, so institutions were asked which preservation/conservation workflows warranted searching metrics. While responses varied widely, the three most common responses were for select general collections conservation treatment (58 


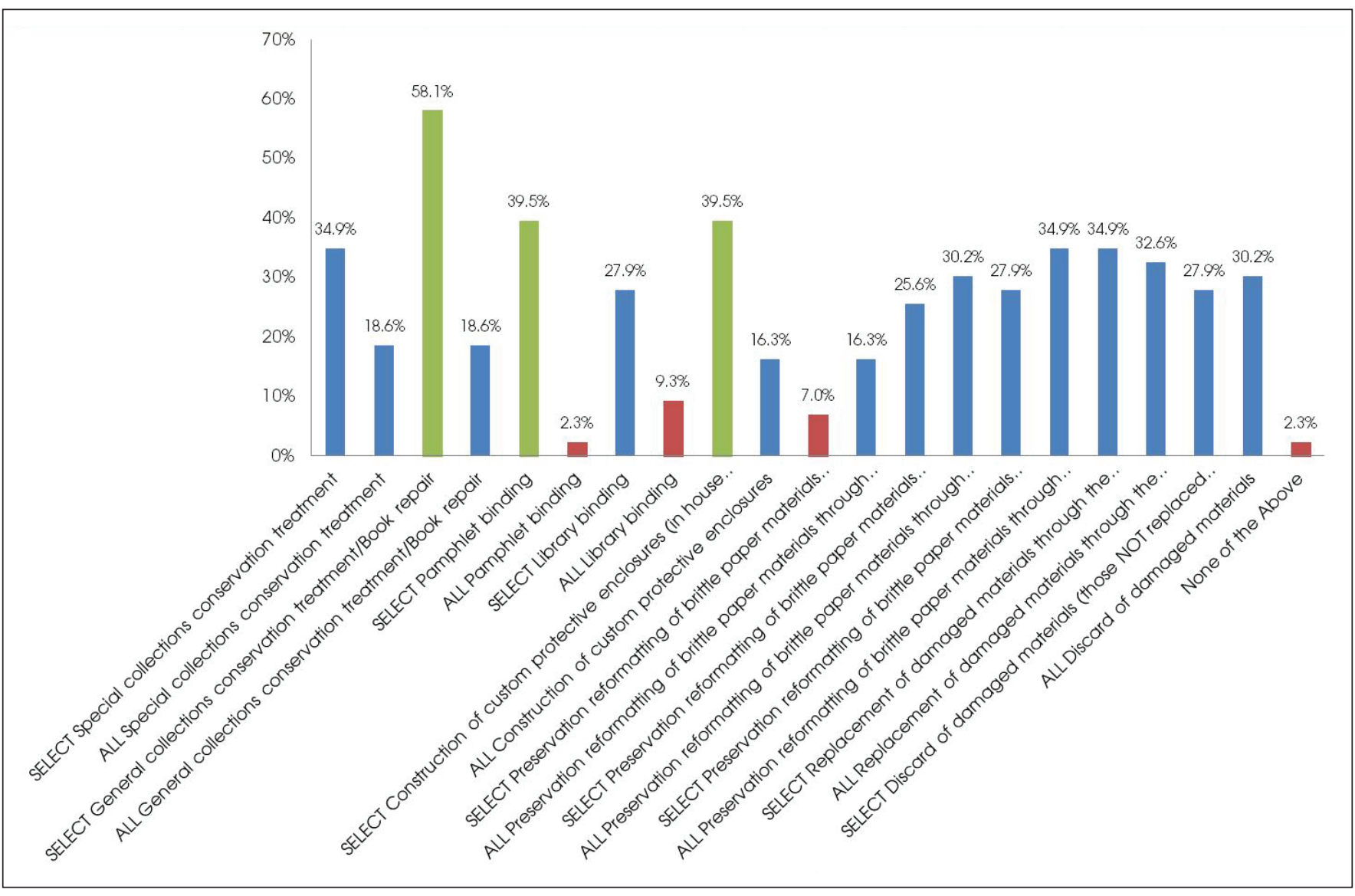

Figure 3. (Question III.5) What types of treatments get preservation metric review?

percent), select pamphlet binding (39.5 percent), and select custom enclosures (39.5 percent) (see figure 3 ). When putting these responses into perspective with the common approaches to library preservation, the responses are not all surprising. General collections conservation is perhaps the area that this sort of searching is most likely to affect (and many institutions wrap pamphlet binding into the same workflows). Since general collections are likely to be more widely held and therefore more likely to have been digitized by a large-scale digitization effort and/or now available electronically, the impact of these metrics would be much higher in general collections than in special collections. Additionally, treatments that are more time intensive (higher-end general collections repairs and construction of custom enclosures) might be more likely targets to remove from workloads to save staff time for other treatments on less accessible materials. Lastly, enclosures might be a target for the application of such metrics as they are not a total solution to a condition problem on an item, but often the only option for items too brittle or damaged be successfully repaired, and thus still pose some access and use challenges, perhaps better solved by steering patrons to alternative resources for that content.

\section{Shared Print Repositories}

Moving from general practices in selection and review, the survey next addressed specifically whether preservation programs consider items for possible incorporation into a SPR when making preservation decisions. This is of significant interest to Illinois, which is partnering in a developing SPR, and has not previously weighed the potential for the Illinois copy to be selected as a copy of record when making treatment decisions. From the data collected in the survey, it appears that Illinois is not alone in this respect-as only 16 percent of respondents answered that this potentiality is considered as part of their preservation review. Of the minority who responded affirmatively, about $2 / 3$ of those (10 percent of the respondents) noted that they regularly perform a physical review of the materials in light of this possibility.

\section{Print Replacements}

The survey next asked respondents if they searched for print replacements before making treatment decisions. Libraries may utilize this method because print copies from the 
resale market may be in better condition than the item being reviewed for preservation action. Additionally, searching for available print replacements is necessary, according to section 108 of US copyright law, before a preservation copy can be made. Survey respondents answered that about 55 percent of institutions look for print replacements in at least some of their workflows, but 36 percent do not. The remaining 9 percent either did not respond or did not know for certain. Of those who consider replacement copies, the majority (75 percent) review the condition of the replacement copy before replacement occurs and of those, most review for completeness (95.2 percent), but the majority also reviews paper strength (85.7 percent) and binding condition (85.7 percent).

\section{Institutional Holdings}

There has been much discussion in the preservation field about the significance of institutional holdings on preservation decision making. Most notably, this has been through Nadal and Peterson's white paper mentioned in the literature review. Nadal and Peterson believe libraries should consider whether individual copy preservation of widely held titles is cost-effective or necessary. In light of this, one of the main topics investigated by this survey was how often libraries are utilizing holdings data when making preservation decisions. Perhaps a bit surprisingly, only 50 percent of the institutions surveyed responded that they collected data on other institutional holdings before any preservation decisions. Forty percent reported that they do not gather this data, and an additional 10 percent thought that another department might do this sort of searching outside of the preservation program (i.e., collection managers may search for this information before sending an item to preservation). For those who evaluated holdings, the survey asked how (geographically) they considered the relevance of reported holdings. Seventy-two percent looked at holdings on a national level, while 48 percent considered holdings on a regional or consortial level ( 75 percent of these looked at this in addition to national holdings). The remaining 20 percent either did not respond, or responded with notes that did not directly tie into the focus of the question. The author was also interested in whether respondents searched monographs or journals, or both, since holdings for journals can be quite problematic due to the need to search individual institutional holdings for meaningful volume level data. Of those who perform such searches, 60 percent searched both monographs and journals, 20 percent searched monographs only, and the remaining 20 percent did not respond to the question. However, no one reported searching only journal holdings.

Lastly, the survey asked how the holdings data collected influenced preservation decision making. Of those who collected holdings data, less than half (48 percent) reported that if holdings were found over a certain threshold (that threshold was not asked to be reported), they would strongly consider discarding/withdrawing a damaged volume over repair. Thirty-six percent reported that if holdings were under a certain threshold, they would consider transferring the item to special collections, and 28 percent reported that if holdings data was over a certain threshold they would not treat the item, but return it to the library untreated. Eight percent of respondents reported "other," which included several responses of "it varies," and noted that holdings data also informs transfer to storage.

Overall, these findings were not surprising, but also not as conclusive as the author hoped. Half of the institutions that replied to the survey responded that they did not consider holdings for any repairs, and for the half that did consider this information at some level, most (as indicated by their responses to question five in section three) only consider the value of institutional holdings for small subsets of items coming in for treatment. While Nadal and Peterson's white paper was groundbreaking in 2011, only two years later, few institutions (less than 25 percent) have implemented any programmatic consideration for discarding a physical monograph or journal in light of broad institutional holdings. As the field adapts to the changing landscape of library print retention, and participation and trust in shared print repositories increases over time, the author anticipates that this number will dramatically increase in the not-sodistant future. Especially as trusted shared print repositories add unique OCLC symbols to indicate when items are held in such a facility, the impact and value of shared print holdings will undoubtedly increase and influence preservation decisions for local holdings.

\section{Availability of Digitized Content}

Another key area of the information the author hoped to gather was the influence of freely available, full-text digital content on preservation selection. Nearly all large and many small libraries have felt the pressure to digitize portions of their collections-either special or general collections or both—as patrons become increasingly reliant upon the ease of access provided by digital content. With that in mind, then, how much are preservation programs relying upon the availability of digitized content to lessen preservation workloads or better target limited resources? Of those surveyed, over half ( 57 percent) reported that they searched for online content, while only 26 percent did not. Of those remaining, 14 percent reported that they believed that this searching was done, but outside the preservation program (again, likely by collection managers or circulation staff), and an additional 3 percent responded that they only searched for availability of digitized content if an item was deemed unrepairable. The survey then delved deeper to see what 
sort of digitized content was being considered for preservation surrogacy, with an assumption that trusted sources such as HathiTrust, JSTOR, and Portico titles would be more heavily regarded than smaller or commercial ventures with no preservation plan in place. Indeed, preservation did rely on these sources more heavily, but a surprisingly high proportion, 26 percent of respondents, relied on any available digitized content, while just 55 percent replied that they only considered openly available digitized content in trusted repositories. For licensed digitized content (predominantly journals), 32 percent replied that they considered the availability of e-resources associated with a third party preservation service (such as LOCKSS or Portico), whereas 36 percent replied that they considered such resources with a vendor supported print repository (such as JSTOR). Lastly, 13 percent replied that they considered the availability of e-resources that were associated with community supported print repositories (CRL being the longest-standing of these, but newer shared print repositories, such as Western Regional Storage Trust (WEST) and others being more recent programs). Only 6.5 percent of those who search for digitized content reported that they would consider digitized content that was not associated with any such preservation services, which is heartening. For those who do utilize digital content in their preservation decision-making, respondents followed a range of different approaches to ensuring the quality of the digital surrogate. Twenty-nine percent reported that they accepted the digital content identified without any review of the quality or completeness, while 22 percent performed cursory or "spot" reviews. Twenty-three percent performed a full review for quality and completeness, but only 3 percent performed a thorough, page-by-page level review of content. With the results of Conway's research on the quality of digitized content in the HathiTrust likely to be published soon, preservation practitioners may be swayed to trust or distrust the quality of such files more soon, and it would be an interesting comparison to revisit this practice in five years to see how the field's perceptions and practices have changed.

Responses to the survey question of how the availability of identified digital content affects preservation treatment decisions were quite diverse. Of those who gathered information on the availability of digitized content, 16 percent replied that if such is available they will return the original to the shelf untreated; 32 percent replied that they would only supply a protective enclosure for the piece (and would not repair it); 29 percent reported that they would withdraw the item; 22 percent reported that the availability of digital content has no bearing on their preservation decision making (though they do search for it); and 16 percent replied with "other" responses. Of those other responses, 80 percent replied that their practice varies depending on the circumstances, and 20 percent responded that they would move the object to storage (but did not say whether they would repair or box the item).

These findings on the utilization of digitized content are significant because a reasonably high percentage of respondents (57 percent) are now relying at least to some degree on the availability of the digitized content to serve a preservation and access function or inform treatment decisions, but less than half of those report performing any level of quality assurance of that content. Thirty nine percent of respondents replied that with the availability of such content, materials are either untreated or discarded. The correlation between these two is disheartening - 42 percent of those replying that they will discard or not repair materials based on available digital content also reported that they do not perform a quality review of the content they have identified. A more positive perspective on this may be that these decisions are being made in concert with other data gathering about long-term preservation. Looking at the collected survey data, 69 percent of those who accept digitized content with little to no review are also checking for wider institutional holdings, while 31 percent are not doing thorough reviews of digital content nor checking for wider holdings. While this data may simply imply that if instructions are thorough in one area of preservation review, they tend to be more thorough in other areas as well, it may have other implications. Perhaps institutions that are not doing a thorough review of digitized content are not doing so because they are relying on the wider print holdings as preservation copies, whereas the available digitized content is considered only an access mechanism or as a preservation copy with an acceptable risk of it being of poor quality. More research in this area would help to clarify if this supposition is accurate.

Allied with the use of digitized content to inform preservation decision making is how institutions call attention to the availability of digital content vis-à-vis the original physical object in hand. Thirty percent of respondents replied that they note on the physical object (or its container) that digital content is also available. This practice does not, however, have a strong correlation between the type of treatment or lack thereof, indicated in the previous question (33 percent of those saying they return items to the shelf or create an enclosure also indicate that they mark the item). However, many more institutions do add notes to the electronic records for the items, with almost 42 percent adding notes in their local ILS and 29 percent adding it to the MARC 583 Action Note field (10 percent doing both), and 23 percent marking items as well as updating the records in some way.

\section{Historic Use of Originals}

When contemplating treatment options, many institutions may also take recorded use of an artifact into account. While all other factors such as national holdings and digital 
surrogates may sway some institutions, many still place great value on the use of the book in question, as this most closely represents the value of that physical item to the institution's patrons. True to this assumption, just under half (49 percent) reported that they programmatically consider use when making preservation treatment decisions, while 7 percent replied that their institution considers this factor, but it is not considered within the preservation program (i.e., considered within other units, likely while selecting materials to send to preservation), while 35 percent of institutions replied that they did not consider use in their decisions. The 9 percent that replied "other" all replied that they do consider use in some occasions, but not systematically. Of course, as stated at the beginning, 98 percent of respondents use circulation (the most common form of use) as a method of selection for preservation action, so while historical use may be considered by 49 percent, active use plays a role for at least preliminary selection for almost all those surveyed. Of those responding that they did consider use on at least one level (65 percent of the total), exactly half replied that if they found use to be over a certain threshold (institutions were not asked to define this threshold within the scope of the survey), the physical item would be treated regardless of holdings or availability of digitized content.

\section{Discussion and Conclusions}

The information gathered from this survey is illuminating in many ways. While the strong trends that the author hoped to see are not as clearly defined as originally anticipated, it is clear from the data that the field of preservation is changing and being strongly influenced by the impact of shared resources, both physical and electronic. Trends in the data seem to indicate that while we as a field are becoming more comfortable with not treating an item if it is widely held or digitized (often times no matter the source), we are not as comfortable with withdrawing damaged materials from our collections. Perhaps this is due to our inherent reluctance to make such a "final" decision as withdrawal when our comfort with both digitized content and shared print repositories is still so new. However, what will become of our collections in the meantime? Will more libraries begin to accept the idea that not repairing an item but also not withdrawing it is an acceptable middle ground to managing shrinking budgets and "hedging our bets"? Or is this level of discomfort sitting not just with preservation, but with the larger academic library collection management approaches? Although the field of academic libraries is rife with discussions of shrinking physical collections, are many of us still feeling local pressures from faculty and our administration to keep books on the shelves? Or, are we still terrorized by the shadow of Nicholson Baker's Double Fold, the negative impact it had on the perceptions of preservation microfilming projects, and the management of brittle newspaper holdings? ${ }^{16}$ Anecdotal discussions with the author's peers imply that these pressures and fears are still very real in many institutions, but further study in this area is necessary to draw any concrete assertions.

While discarding books is seen by many as a hard line approach, it may in the end be better service to our patrons and any future of shared collections. By continuing to provide physical access to poor condition copies, we appear as poor stewards of our physical collections. More importantly, by not discarding, are we considering that at some point in the future they may be repaired? If so, why and when? Will they be returning to our programs in the future for re-evaluation (meaning more staff time resulting in potential repeated inaction)? Or worse yet, being sent out of our circulating collections into storage collections? Whereas this final option may seem appealing as it takes the item out of the circulating collection, for many institutions this may open the damaged copy up to inclusion in future shared print repositories. While the utopian vision of a national "preservation collection" may not be a realistic near-term goal for many reasons, we must work collaboratively to ensure that those materials being included in our shared print repositories are at the very least complete and intact, and ideally in good physical condition. Clearly, generally agreed upon MARC record updates will be necessary to exclude such possibilities in the future, but this discussion is still occurring and libraries are by no means following widely agreed upon procedures. Although the Library of Congress published its Preservation and Digitization Actions: Terminology for MARC 21 Field 583 (often referred to as PDA) in 2004, and discussions of its use and applications occurred at the American Library Association's Annual Conference as recently as 2011 and in McCann's recent article "Conservation Documentation in Research Libraries: Making the Link with MARC Data," no agreed upon procedure for record sharing in anticipation of share print holdings exists. ${ }^{17}$

\section{Next Steps}

The intent of this paper is to provide a snapshot into how broader access to content is currently affecting preservation selection. The results have illuminated a time of transition. A future survey in five years will likely show even greater reliance on shared access to both physical and digital content. Likewise, as our reliance on digital content develops, we will most likely see our understanding of the reliability of the quality of that content and the value of that quality increase as well.

Case studies, such as that published by Nadal and Peterson and research being undertaken by Conway, will be invaluable as library preservation programs begin to navigate 
this sea of change. Further professional discussion of the use of shared MARC data and its role in share collection development is also necessary if libraries are to be able to consider the long-term effects of preservation decisions made soon.

\section{References}

1. Kathleen Arthur et al., Recognizing Digitization as a Preservation Reformatting Method (Washington, DC: Association of Research Libraries, 2004, accessed August 28, 2013, http:// chnm.gmu.edu/digitalhistory/links/pdf/preserving/8_34a.pdf.

2. Oya Reiger, Preservation in the Age of Large-Scale Digitization: A White Paper (Washington, DC: Council on Library in Information Resources, 2008), accessed August 28, 2013, www.clir.org/pubs/reports/pub141/pub141.pdf.

3. Paul Conway, "Measuring Content Quality in a Preservation Repository: HathiTrust and Large-scale Book Digitization," in Proceedings of 7th International Conference on Preservation of Digital Objects (iPres 2010), 19-24 September, Vienna, Austria, ed. Andreas Rauber et al. (Vienna, Austria: Österreichische Computer Gesellschaft, 2010), 95-102, accessed August 28, 2013, http://hdl.handle.net/2027.42/85227; Paul Conway, "Archival Quality and Long-term Preservation: A Research Framework for Validating the Usefulness of Digital Surrogates," Archival Science 11, no. 3-4 (2011): 293-309. Project website available at http://hathitrust-quality.projects si.umich.edu/.

4. Willis E. Bridegam, "Print Preservation at the Local LevelThe Five College Experience," Library Collections, Acquisitions \& Technical Services 28, no. 1 (2004): 29-38, dx.doi .org/10.1016/j.lcats.2003.11.005.

5. Lizanne Payne, Library Storage Facilities and the Future of Print Collections in North America (Dublin, OH: OCLC Program and Research, 2007), accessed August 28, 2013, www .oclc.org/research/publications/library/2007/2007-01.pdf.

6. Robert H. Kieft and Lizanne Payne, "A Nation-Wide Planning Framework for Large-Scale Collaboration on Legacy Print Monograph Collections," Collaborative Librarianship 2, no. 4 (2010): 229-33, accessed August 28, 2013, http:// collaborativelibrarianship.org/index.php/jocl/article/viewFile/ 119/77.

7. "Maine Shared Collections," University of Maine, accessed February 4, 2014, www.maineinfonet.net/mscs.

8. HathiTrust, HathiTrust Distributed Print Monographs Archive Proposal (August 23, 2011), accessed September 3, 2013, www.hathitrust.org/constitutional_convention2011_ ballot_proposals\#proposall.

9. Candace A.Yano, Z.J. Max Shen, and Stephen Chan,
"Optimizing the Number of Copies for Print Preservation of Research Journals” International Journal of Production Research, 51 no. 23/24 (December 2013): 7456-69.

10. Roger Schonfeld and Ross Hoursewright, What to Withdraw? Print Collections Management in the Wake of Digitization (New York: Ithaka S+R Research and Consulting, 2009), accessed February 12, 2014, www.sr.ithaka.org/research -publications/what-withdraw-print-collections-management -wake-digitization

11. Jacob Nadal and Annie Peterson, "Scarce and Endangered Works: Using Network-level Holdings Data in Preservation Decision Making and Stewardship of the Printed Record" (preprint, accepted for publication in ALCTS Monographs, Los Angeles: University of California Los Angeles, 2011), accessed August 28, 2013, www.jacobnadal.com/wp-content/ uploads/2011/05/Scarce\%20and\%20Endangered\%20Works\% 28v19Sept2011\%29.pdf.

12. Lars Meyer, Safeguarding Collections at the Dawn of the 21st Century: Describing Roles \& Measuring Contemporary Preservation Activities in ARL Libraries (Bethesda, MD: ERIC Document Reproduction Service, ED 505512, 2009) accessed August 28, 2013, http://files.eric.ed.gov/fulltext/ ED505512.pdf.

13. Paul Conway, "Preservation in the Age of Google: Digitization, Digital Preservation, and Dilemmas," The Library Quarterly 80, no. 1 (2010): 61-79, accessed August 28, 2013, www.jstor.org/stable/10.1086/648463.

14. Carline Peach and Julia Foster, Knowing the Need: Optimising Preservation for Library and Archive Collections (London: Preservation Advisory Centre, The British Library, 2013) accessed August 28, 2013, www.bl.uk/blpac/pdf/ktn.pdf.

15. A Public Trust at Risk: the Heritage Health Index Report on the State of America's Collections (Washington, DC: Heritage Preservation, 2005), accessed August 28, 2013, www.heritage preservation.org/HHI/HHIfull.pdf; Alison Walker and Julia Foster, Knowing the Need: A Report on the Emerging Picture of Preservation Need in Libraries and Archives in the UK (London: National Preservation Office, British Library, 2006) accessed August 28, 2013, www.bl.uk/blpac/pdf/knowing.pdf.

16. Nicholson Baker, Double Fold: Libraries and the Assault on Paper (New York: Random House, 2002).

17. Network Development and MARC Standards Office, Library of Congress, Preservation \& Digitization Actions: Terminology for MARC 21 Field 583 (2004), accessed August 28, 2013, www.loc.gov/marc/bibliographic/pda.pdf; Laura McCann, "Conservation Documentation in Research Libraries: Making the Link with MARC Data," Library Resources \& Technical Services 57, no. 1 (2013): 30-50. 


\title{
Appendix. Copy of Survey Form
}

\author{
Online Consent \\ Prioritization for Preservation Treatment Decision Making in a Collaborative Library Environment
}

You are invited to participate in a research study to document current practices and trends in preservation and conservation decision making based on the availability of physical and digital surrogates as practiced in libraries. It is being conducted by Jennifer Hain Teper, Head of Preservation and Conservation at the University Library and Sylvie Rollason-Cass, graduate student, at the University of Illinois Urbana-Champaign.

This study will take approximately 10-20 minutes of your time. You will be asked to complete an online survey about your institutional practices in selecting materials for preservation action. Your decision to participate or decline participation in this study is completely voluntary and you have the right to terminate your participation at any time without penalty. You may skip any questions you do not wish to answer. If you want do not wish to complete this survey just close your browser. Your participation in this research will be completely confidential and data will be averaged and reported in aggregate. Possible outlets of dissemination may be peer reviewed journal articles and professional conference presentations.

Although your participation in this research may not benefit you personally, it will help us understand how the effects of available digital surrogacy and shared print repositories are changing the way preservation decisions are being made. There are no risks to individuals participating in this survey beyond those that exist in daily life.

If you have questions about this project, you may contact the Principal Investigator at 217-244-5689, or jhain@illinois .edu. If you have any questions about your rights as a participant in this study or any concerns or complaints, please contact the University of Illinois Institutional Review Board at 217-333-2670 (collect calls will be accepted if you identify yourself as a research participant) or via email at irb@illinois.edu.

Please print a copy of this consent form for your records, if you so desire.

I have read and understand the above consent form, I certify that I am 18 years old or older and, by clicking the submit button to enter the survey, I indicate my willingness voluntarily take part in the study.

- (Submit) I have read the description and agree to participate in this study

- (Decline) I have read the description and do not wish to participate in this study

\section{Section I: General Information}

1. What position do you currently hold? (select one answer that best describes your position)
o Preservation Professional
- Preservation Support Staff
- Conservation Professional
- Conservation Support Staff
- Collection Management Librarian
Collection Management Staff
Other
$\circ$ Enter text:

2. What type of institution do you currently work in?

- US/Canada ARL institution

- US/Canada non-ARL institution

- Non-US research library

$\circ$ Non-US non-research library

o Other

$\circ$ Enter text

3. What is the total collection size in your institution?

- Under 1 million volumes

- 1-3 million volumes

○ 3-5 million volumes

\begin{abstract}
○ 5-8 million volumes
- 8 or more million volumes

$\circ$ Other
\end{abstract}

\section{Section II: Current Preservation Practices}

Please answer the following in FTE where one FTE $=40$ hours/week for $50+$ weeks per year. A less than full-time position appointed for less than a full year would be calculated as follows: 1 half time position working for 9 months would equal .5 (hrs/week) × .67 (months/year), or .33 FTE.

1. What is your current preservation and/or conservation staff in FTE (full-time equivalents). Please include any paid or volunteer labor you have within the preservation/conservation program currently, in aggregate. Please do NOT include other FTE outside of the formal preservation/conservation program or unit. answer must be numeric

2. Which preservation action(s) does your institution undertake? (select as many as apply)

- Special collections conservation treatment

- General collections conservation treatment/Book repair 
○ Pamphlet binding

$\circ$ Library binding

- Construction of custom protective enclosures (in house or purchased)

- Preservation reformatting of brittle paper materials through microfilm

- Preservation reformatting of brittle paper materials through digitization

o Preservation reformatting of brittle paper materials through "preservation photocopy" replacements

- Replacement of damaged materials through the purchase of available replacement copies (used book market)

- Discard of damaged materials (those NOT replaced through reformatting or replacement copies)

3. Describe how your preservation staffing has changed (if at all) to meet the changing preservation needs of libraries, such as digital preservation, media preservation, and the effects of digital access to traditionally paper collections. If your preservation staffing has not changed, please select the default of «no change»

4. How are materials identified for preservation action? (select as many as apply)

o Circulation

- Curatorial review

- Interlibrary Loan

○ Collection shift/relocation projects

$\circ$ Exhibits

○ At shelf

o Other

$\circ$ Enter text:

\section{Section III: Selection for Preservation}

1. Do you consider the possibility of a piece being incorporated into a Shared Print Repository when evaluating items for repair?

$\circ$ Yes (continue to question 2)

$\circ$ No (skip to question 3)

2. If yes, have you implemented physical review procedures to ensure the completeness and/or soundness of the copy?

$\circ$ Yes

$\circ$ No

- If yes, please describe your review procedures briefly.

$\circ$ Enter text:
3. Does your institution undertake any of the following procedures when considering treatment (repair, reformatting or boxing) of materials: Search for print replacement copies; Search for availability of national, regional, or consortial holdings; Search for availability of digitized content; or Collect historical circulation/ use statistics?

$\circ$ Yes

- No (No further responses are required-you may exit the survey)

4. If any of the above are selected, how much time, on average, do staff spend in aggregate for reviewing each item prior to making treatment decisions?
○ 0-2 mins
○ 3-5 mins
○ 6-10 mins
○ 11-15 mins
- 16-20 mins
○ 20-30 mins
$\circ$ Other
$\circ$ Enter text:

Select all that apply.

5. If any of the above are selected, what types of treatments are given this level of review/consideration?

- SELECT Special collections conservation treatment

- ALL Special collections conservation treatment

- SELECT General collections conservation treatment/Book repair

- ALL General collections conservation treatment/ Book repair

- SELECT Pamphlet binding

- ALL Pamphlet binding

- SELECT Library binding

$\circ$ ALL Library binding

- SELECT Construction of custom protective enclosures (in house or purchased)

- ALL Construction of custom protective enclosures

- SELECT Preservation reformatting of brittle paper materials through microfilm

- ALL Preservation reformatting of brittle paper materials through microfilm

- SELECT Preservation reformatting of brittle paper materials through digitization

- ALL Preservation reformatting of brittle paper materials through digitization

- SELECT Preservation reformatting of brittle paper materials through "preservation photocopy" replacements

- ALL Preservation reformatting of brittle paper 
materials through "preservation photocopy" replacements

- SELECT Replacement of damaged materials through the purchase of available replacement copies (used book market)

- ALL Replacement of damaged materials through the purchase of available replacement copies

- SELECT Discard of damaged materials (those NOT replaced through reformatting or replacement copies)

$\circ$ ALL Discard of damaged materials

\section{Section IV: Print Replacement}

1. Does your institution search for print replacements prior to making treatment decisions?

$\circ$ Yes

$\circ$ No-Please advance to Section V: Holdings

$\circ$ I think so, but don`t know any specifics (done in another department)_Please advance to Section

V: Holdings

o Other

○ Enter text:

2. When searching for availability of print replacement copies, do you: (check all that apply)

- Search only for exact replacements of the title (same publisher, edition, and year)

- Search for "similar" replacements of the title (different editions, publishers, etc)

3. Do you evaluate the physical condition of the replacement copy before bringing it into the collection?

$\circ$ Yes

$\circ$ No

4. 4 If yes, what are your criteria for evaluation before replacement? (check all that apply)

$\circ$ Completeness

$\circ$ Paper strength

$\circ$ Binding condition

$\circ$ Binding format (original cover vs. rebound)

o Other

\section{Section V: Holdings}

1. Does your institution search for the availability of other institutional holdings prior to making treatment decisions?

$\circ$ Yes

- No-Please advance to Section VI: Digital Surrogates

○ I think so, but don`t know any specifics (done in another department)—Please advance to Section

VI: Digital Surrogates

$\circ$ Other

$\circ$ Enter text:

2. When searching for availability of other institutional holdings, do you search for: (select all that apply)

- Number of holdings on a national basis

- Number of holdings on a consortial, regional, and/ or state-wide basis

o Other

$\circ$ Enter text:

3. Do you search availability for monographs and journals?

- Monographs or monographic sets only

$\circ$ Journals only

$\circ$ Monographs and journals

4. How does the availability of holdings at other institutions affect your local preservation treatment decisions? (check all that apply)

- If over a certain number, will not treat (return to shelf untreated)

- If over a certain number, will discard/withdraw

o If under a certain number, will move to special collections

- Holdings have no bearing on treatment decisions

$\circ$ Other

$\circ$ Enter text:

5. Describe how holdings data influence your decision to discard (or retain) a damaged copy, for example: "to discard an item, we require at least 3 holdings in our state and 26 holdings nationally."

\section{Section VI: Digital Surrogates}

1. Does your institution search for the availability of digitized content prior to making treatment decisions?

$\circ$ Yes

- No-Please advance to Section VII: Use

- I think so, but don`t know any specifics (done in another department)—Please advance to Section VII: Use

$\circ$ Other

$\circ$ Enter text:

2. When searching for availability of available digital content, do you search for: (select all that apply)

○ Availability of ANY openly available digitized content

- Availability of openly available digitized content in a trusted digital repository, only. 
- Availability of licensed digitized content (such as many electronic journals) associated with a third-party preservation service (through Portico, LOCKSS, CLOCKSS)

- Availability of licensed digitized content associated with known vendor supported print repository (such as JSTOR)

- Availability of digitized content associated with known community supported print repositories (WEST or CRL, for instance)

$\circ$ Availability of digitized content NOT associated with a third-party preservation service, nor print repository

o Other

$\circ$ Enter text:

3. If you use ANY of the above digital content for preservation purposes, do you:

- Accept the digitized content without review

○ Perform cursory (spot) review of quality/completeness of digitized content

- Perform full review of legibility and completeness

- Perform extensive page-level examination

4. How does the availability (assuming it meets any quality review) of digital content affect your local preservation treatment decisions?

o If available, will not treat physical item (return to shelf untreated)

- If available, will provide protective enclosure only

$\circ$ If available, will discard/withdraw

- Availability has no bearing on treatment decisions

o Other

$\circ$ Enter text:

5. If you maintain the physical item, do you mark the item or enclosure in any way to indicate the availability of digitized content:
$\circ$ Yes
$\circ$ No
$\circ$ Other
$\circ$ Enter text:

6. Once digitized content is identified, do you add a link or note about the availability in any of the following?

- Local ILS

- MARC 583 field

o Other

○ Enter text:
7. Are there any procedures in place for your library to scan and supplement an existing, externally managed digital file (for missing text, illustrations, foldouts or pocketed materials, for instance)?

$\circ$ Yes

$\circ$ No

- Other

○ Enter text:

\section{VII: Use}

1. Does your institution search for history of use prior to making treatment decisions?

$\circ$ Yes

$\circ$ No-No further questions

○ I think so, but don't know any specifics (done in another department)—no further questions

$\circ$ Other

$\circ$ Enter text:

2. If yes, please describe how and if a specific time inter$\mathrm{val}$ (e.g. X circulations in the last 10 years) is utilized.

o If over a certain number of uses, item will be treated regardless of holdings or availability of digitized content.

- Other

○ Enter text:

\section{Survey Wrap-Up}

1. Please add any additional comments either about your preservation practices or about your responses here:

2. Would you be willing to be contacted for further details regarding your responses to these questions?

$\circ$ Yes

$\circ$ No

3. If yes, please enter your contact information below, including name, institution, and preferred contact information (phone number or e-mail): 